\title{
Application of Cloud Educational Technologies for Teacher Competence Development
}

\author{
Iurii L. Mosenkis \\ Taras Shevchenko National University of Kyiv, Ukraine \\ https://orcid.org/0000-0002-9957-0585 \\ Liudmyla V. Lukianyk \\ Rivne State University of Humanities, Ukraine \\ https://orcid.org/0000-0003-3432-1614 \\ Oleksandr M. Strokal \\ Taras Shevchenko National University of Kyiv, Ukraine \\ https://orcid.org/0000-0002-9229-2711 \\ Vira A. Ponomarova \\ Taras Shevchenko National University of Kyiv, Ukraine \\ https://orcid.org/0000-0003-1880-4691 \\ Hanna V. Mykhailiuk \\ Borys Grinchenko Kyiv University, Kyiv, Ukraine \\ https://orcid.org/0000-0002-4734-7031
}

\begin{abstract}
The research deals with solving an urgent pedagogical problem - finding ways for teacher competence development based on the use of innovative educational technologies that meet the modern requirements of society, pedagogical science and practice. It is established that the educational process on-line can be managed with the use of cloud technologies that influence the architecture, the services provided and the logistics of implementation of training courses. The experimental use of Google Apps Education Edition and OwnCloud was tested in distance training courses for teacher competence development with up to 10 years of practical experience. The obtained results and the dynamics of the development of the motivational, cognitive, activity and personal components of teacher competences were analysed using the methods of mathematical statistics. This study reveals that Google Apps Education Edition has powerful tools and extensive opportunities for distance learning, and is an effective means of enhancing the development of all components of teacher competence. The use of these services in the process of distance learning courses to increase teacher competence almost completely solves the problem of interaction with the teaching staff and the learning environment. This helps to establish the
\end{abstract}


correspondence of the content of assignments to the studied topics and to ensure a professional focus of project assignments of teachers. This model can be used to develop and implement services that allow the organization of personal information space for teachers (on the example of blogs and Google cloud service).

Keywords: cloud learning technologies; Google Apps Education Edition services; distance competence; development courses

\section{Introduction}

With a wide spread of digital technologies, learning takes the form of a continuous, individually oriented, flexible and dynamic process. Global trends in improving technologies and ways of obtaining, processing and transferring information open up new educational opportunities (Haris \& Khan, 2018). The development of information technology, the use of the Internet, the networking of educational organizations, e-learning necessitate the study of the training and competence development of teachers, taking into account the priority areas of digitalization of society (Admiraal \& Berry, 2016). The world educational space is expanding the use of electronic means, technologies and resources using the Internet and various innovative technologies (Maican \& Lixandroiu, 2016). The dynamic development of information technology and, as a consequence, the changing requirements for educational activities are in line with the level of teacher competence development level (Khedr \& Idrees, 2017; Singh \& Baheti, 2017). The emergence of new forms of organization of the educational process and increasing the range of educational tools, technologies and educational services make new demands on the teacher competence in an electronic information educational environment. The continuity of professional education, the expansion of basic skills, independent continuing of study are all necessary for teachers to develop their competence and improve pedagogical skills (McKenney, 2018). In this regard, e-learning, including mass open online courses and cloud-based learning technologies, becomes increasingly widespread.

The urgency of using cloud-based learning technologies in developing teacher competence is dictated, first of all, by the pedagogical needs for improving the learning performance (Hidayat \& Utomo, 2014). Competence orientation of the learning process is characterized by increasing dynamics of the educational process, a significant increase in the role of distance learning technologies, as well as the global transition of information resources in the virtual environment. All this encourages educational institutions to adopt innovative models of activity. Therefore, the optimization of adult (teachers) learning involves the use of information and communication technology platforms, smartphones, learning management systems (Jain \& Pandey, 2013; Odeh, Garcia-Perez \& Warwick, 2017; Prescott, 2014). Cloud technologies optimize the collection, systematization, storage, retrieval, processing and presentation of information, are of general educational importance and can be used in the study of all subjects (Sultan, 2010). The great value of incorporating cloud technology into the educational process is the ability to increase time for learning without changing the curricula of educational institutions (Lakshminarayanan, Kumar \& Raju, 2014). 
The issue of application of cloud technologies in the educational process is determined by a number of their advantages. First, they provide on-demand selfservice, i.e. the users' ability to use computing resources to the required extent without the provider's (system administrator's) consent. Second, the combination of resources is a dynamic redistribution of capacity (storage devices, RAM, network bandwidth, etc.) (Etawi, 2018). Third, the distribution of resources between multiple data centers allows the use of IT resources by different applications and users in an incoherent mode $(\mathrm{Su}$, Tzeng \& $\mathrm{Hu}, 2016)$. They also provide universal network access - the users receive cloud services regardless of the terminal device used via the Internet from high-tech data centers. Another advantage of cloud technologies is the elasticity ("infinite" scalability) of services, provides access to the system even in the "peak" of requests, and the list of services can expand or narrow automatically, without additional interaction with the provider (Kleftodimos \& Evangelidis, 2016) and consumption record (payment upon use). In spite of the above, the researches show that theoretical prerequisites on the issues of informatization of education and competence development of specialists with the use of different pedagogical technologies have been formed so far, but there is a lack of research examining the use of cloud educational technologies for the competence of teachers.

\subsection{Research questions}

The objective of this study was to determine 1) how and to what extent the distance learning program based on Google Apps Education Edition and OwnCloud can contribute to the learning process and increase the teacher competence; and 2) how teachers perceived the program of the distance qualification courses?

\subsection{Literature Review}

Literature review showed that teacher competence functions under the conditions of totally innovative realities of the modern world, high rate of knowledge updating, blurring the boundaries of teaching as its system-building element (Vangrieken, Dochy, Raes \& Kyndt, 2015). Having a range of professionally significant functions (ability to reflect, creativity, self-organization, selfdevelopment, selectivity, manifestation of creating content, innovative solutions) (Lauermann \& König, 2016; van Leeuwen, Janssen, Erkens \& Brekelmans, 2015) in conjunction with professional skills allow teachers to act as reflective agents of industrial and socio-cultural innovations, which ensures their personal and professional success.

The expansion of teaching activities - collaboration, counselling, tutoring, monitoring - necessitates building competence and realizing skills within computer-assisted communication (Yousafzai, Chang, Gani \& Noor, 2016). It also urges the search for alternatives to traditional forms of organization of the educational process, creating opportunities for personal learning, interactive classes and group teaching (Nosenko, Popel \& Shyshkina, 2018). It should be noted that the organization of advanced teacher training has some features. The work which states that the diversity of existing online services requires their analysis and evaluation for the purpose of selection for use in the curriculum (Diaby \& Rad, 2017; Kaur, 2016) is interesting for the achievement of the research 
objectives. Of course, such selection should be made taking into account the educational potential of services, the possibility and reasonability of their use in the educational process (Narayana, Kumar \& Jayashree, 2017). Building the teacher competence based on cloud technologies should be aimed not only at studying the actual specific services and technologies, but also at mastering the methods of their use in educational activities (Chhabra \& Dixit, 2015; Kaur, 2015). In this regard, the organization of teacher competence building provides review lectures of an introductory nature, as well as practical classes, where the teachers will consider specific examples of the use of cloud technologies and services, and round tables where they can discuss and "play through" learning situations using a variety of online services. We base our belief on the study of the researches (Elmonem, Nasr \& Geith, 2016; Admiraal \& Berry, 2016; Bulla, Hunshal \& Mehta 2016; Hidayat \& Utomo, 2014; Kleftodimos \& Evangelidis, 2016).

\section{Materials and Methods}

The study was prolonged and was conducted using general scientific theoretical, empirical (pedagogical observation, questioning, experiment) and statistical (quantitative and qualitative analysis of experimental results) methods of research and analysis of results according to the objective of each stage. The structure of the pedagogical experiment included three stages: diagnostic (primary diagnosis of the level of teacher competence), formative and final stages. The research work was based on the use of the following experimental methods: questionnaires, testing, laboratory research work, defence of projects, element-by-element analysis, peer assessment, computer processing of research results; methods of mathematical processing of research results. The general scheme of organization of research work was as follows: a survey was conducted; project topic, project requirements were developed; the elements for element-by-element analysis were selected; weight points were distributed; peer assessment of projects was carried out by opponents. According to the tasks of the research and the main characteristics of teaching activity, the structural components of teachers' competences are distinguished: motivational, cognitive, activity and personal. The outlined components became the basis for distinguishing the basic, reproductive and creative levels of teachers' competence development.

\subsection{Population Sampling}

The general population of the sample of the survey conducted during 2016-2019 was 311 teachers of different subjects from the National Pedagogical Dragomanov University (93), South Ukrainian National Pedagogical University named after K. D. Ushynsky (84), Ternopil Volodymyr Hnatiuk National Pedagogical University (65), Sumy State A. S. Makarenko Pedagogical University (69) with approximately the same work experience. To organize the experiment, the teachers who participated in the experiment during 2016-2019 were divided into experimental and control groups (Table 1).

Table 1: Number of students in experimental and control groups

\begin{tabular}{|l|c|c|}
\hline Year & Experimental group & Control group \\
\hline $2016-2017$ & 60 & 55 \\
\hline $2017-2018$ & 45 & 48 \\
\hline $2018-2019$ & 24 & 30 \\
\hline
\end{tabular}


Non-variational conditions in CG and EG were the conduct of experimental research during the study of the same subjects and the use of the same forms of control. CG teachers' training was carried out according to the traditional method of advanced training (full-time, full-time and part-time). Variational conditions included the implementation of cloud-based learning technologies in the EG in the distance competence development courses for teachers. Experimental verification of teachers' competence level was based on a level approach (Livingston, 2014), according to which teachers' competence levels were determined with the use of cloud technologies: basic reproductive, creative.

Based on the research (Livingston, 2014; Simaiya \& Paul, 2018), teachers' competence level assessment is presented in the form of:

$$
u=\min \left\{u_{3}, u_{y}, u_{o}\right\},
$$

where $u$ - conditional index number of teachers' competence level, where: 0 initial; 1 - basic; 2 - reproductive; 3 - creative;

$u_{3}$ - conditional index number of the level of knowledge of teachers, where: 0 initial; 1 - basic; 2 - reproductive; 3 - creative;

$u_{y}$ - conditional index number of the level of teachers' skills, where: 0 - initial; 1

- basic; 2 - reproductive; 3 - creative;

$u_{o}$ - conditional index number of the level of experience of teachers, where: 0 initial; 1 - basic; 2 - reproductive; 3 - creative.

Testing based on Google Forms was implemented in self-preparation mode directly to control knowledge. Therefore, the level of motivation for teaching was assessed by performing laboratory research work; the level of knowledge of teachers - in each disciplinary section (topic) based on the results of the final diagnostic work (practical, control and independent work). The content of control measuring materials covers all sections and topics that were studied within the distance competence building courses by means of cloud services. The teachers' skills were assessed based on the results of the defence of final project work on a dichotomous measurement scale, as well as practical tasks, independent (individual, group) and tests, observation, participation in research (preparation of reports for conferences). The level of teachers' experience was assessed based on the results of the defence of the project research work, which was performed within professional activity. The total number of assignments is a multiple of three - the number of identified levels. The results of the current control and intermediate appraisal formed the rating of teachers. Based on the rating scale adopted in higher educational institutions (60-74/75-89/90-100 points), the corresponding points were accrued for the relevant types of work (Table 2).

Table 2: Distribution of points for the types of work within the experimental study

\begin{tabular}{|l|c|c|c|}
\hline \multirow{2}{*}{ Types of training work } & \multicolumn{3}{|c|}{ Levels } \\
\cline { 2 - 4 } & Basic & Reproductive & Creative \\
\hline Laboratory research work & $10-13$ & $14-16$ & $17-20$ \\
\hline Individual works & $10-13$ & $14-16$ & $17-20$ \\
\hline Test papers & $5-6$ & $7-8$ & $9-10$ \\
\hline Testing & $5-6$ & $7-8$ & $9-10$ \\
\hline
\end{tabular}


It was assumed that the theoretical model of the distribution of the data obtained from the experiment is a normal distribution, since the random variables obtained from the analysis are the sum of a large number of weakly dependent terms. Mathematical processing of average scores was carried out using a data analysis tool - descriptive statistics from the Microsoft Excel 2007 software package. This statistical analysis allowed assessing the level of effectiveness of teacher competence through the use of cloud technologies and services due to the interpretation of the level of the average score on the set of competence components identified.

At the pre-experimental stage, the teachers performed the input diagnostic work with the outlined diagnostic tools, and its results are presented in Table 3. It follows from its analysis that all participants of the pedagogical experiment successfully completed the input diagnostic work and were admitted to participate in the pedagogical experiment. Experimental and control groups were formed according to the results of the input diagnostic work.

Table 3: Results of input diagnostic work of teachers' competence at the preexperimental stage

\begin{tabular}{|c|c|c|c|c|c|c|}
\hline \multirow[t]{3}{*}{ Groups } & \multicolumn{6}{|c|}{$\begin{array}{c}\text { Levels of teachers' competence development levels according to the results } \\
\text { of input diagnostic work }\end{array}$} \\
\hline & \multicolumn{2}{|c|}{ Basic } & \multicolumn{2}{|c|}{ Reproductive } & \multicolumn{2}{|c|}{\begin{tabular}{|l} 
Creative \\
\end{tabular}} \\
\hline & No. of teachers & $\%$ & No. of teachers & $\%$ & No. of teachers & $\%$ \\
\hline \multicolumn{7}{|c|}{$2016-2017$} \\
\hline $\mathrm{CG}$ & 33 & $60 \%$ & 17 & $31 \%$ & 5 & $9 \%$ \\
\hline EG & 39 & $65 \%$ & 15 & $25 \%$ & 6 & $10 \%$ \\
\hline \multicolumn{7}{|c|}{$2017-2018$} \\
\hline $\mathrm{CG}$ & 27 & $56.25 \%$ & 15 & $31.25 \%$ & 6 & $12.5 \%$ \\
\hline EG & 23 & $51.1 \%$ & 17 & $37.8 \%$ & 5 & $11.1 \%$ \\
\hline \multicolumn{7}{|c|}{$2018-2019$} \\
\hline $\mathrm{CG}$ & 18 & $60 \%$ & 11 & $36.7 \%$ & 1 & $3.3 \%$ \\
\hline EG & 16 & $66.7 \%$ & 7 & $29.2 \%$ & 1 & $4.1 \%$ \\
\hline
\end{tabular}

At the beginning of the experiment, comparisons of the division of teachers by levels of academic achievement were made. The purpose of this statistical operation is to confirm the insignificant difference between the academic achievement of the competence development of EG and CG teachers. We used $\chi^{2}$ criterion to test the null hypothesis $\left(H_{0}\right)$ that there is no difference between the distribution of students in the two groups by level of academic achievement. According to the results of the input testing (by years), statistical evaluation was performed based on the homogeneity criterion $\chi^{2}$.

The empirical value of $\chi_{e m p}^{2}$ was calculated by the formula:

$$
\chi_{\text {emp }}^{2}=N \cdot M \cdot \sum_{i=1}^{L} \frac{\left(\frac{n_{i}}{N}-\frac{m_{i}}{M}\right)^{2}}{n_{i}+m_{i}},
$$


$L$ - number of gradations of levels of teacher competence development levels. $N$ and $M$ - respectively, the volumes of the experimental and control groups; $n_{i}$ - number of EG students who showed a certain level of competence (basic, reproductive, creative);

$m_{i}$ - the number of CG students who showed a certain level of competence (basic, reproductive, creative).

Two hypotheses we put forward to establish matches or differences in the characteristics of CG and EG.

$H_{0}$ (null hypothesis) - there are no differences between EG and CG teachers in terms of compared characteristics.

$H_{1}$ (alternative hypothesis) - differences between EG and CG teachers in terms of compared characteristics are significant.

Comparison of the values of the criterion $\chi^{2}$ with the critical one $\left(\chi_{0.05}^{2}=5.99\right)$ allowed noting that the characteristics of the samples coincide at the significance level of 0.05 and the EG and CG splitting in the chosen way is possible, therefore the hypothesis $H_{0}$ is accepted. The results are shown in Table 4.

Table 4: Values of the $\chi_{\text {emp }}^{2}$ criterion by years of pre-experimental study

\begin{tabular}{|l|c|c|c|}
\hline Year & $\mathbf{2 0 1 6 - 2 0 1 7}$ & $\mathbf{2 0 1 7 - 2 0 1 8}$ & $\mathbf{2 0 1 8 - 2 0 1 9}$ \\
\hline$\chi_{\text {emp }}^{2}$ & 0.364 & 0.440 & 0.344 \\
\hline
\end{tabular}

\subsection{Research Design}

In order to improve the competence of teachers, distance competence development courses have been developed by means of cloud services. Within the study, the main category of trainees were practitioners with a work experience of no more than 10 years. The teachers chose Google online portal as an online platform for the practical assignments. The choice of using Google Apps Education Edition in remote teacher competence development courses is due to the following reasons: minimum hardware requirements (prerequisite is Internet access); cloud technology does not require any funds for purchasing and maintaining specialized software (the applications can be accessed through a web browser window); Google Apps supports all operating systems and client programs used by teachers and educational institutions; working with documents is possible with any mobile device that supports the Internet; All Google Apps Education Edition tools are free allowing synchronous mobile communication mechanism (confirmations, notifications, reminders), online help system.

Distance competence building courses for teachers were based on the use of special software:

- Google services (Google Classroom, Google Mindmeister, Google Docs, Google Spreadsheets, Google Presentation, Google Forms);

- QR code generator QR coder;

- mobile service QR scanner;

- online designer of interactive assignments LearningApps;

- service for organizing interactive testing, surveys and quizzes (Socrative, PollEverywhere). 
The main Google services used by teachers for their competence development were: Google Drive - for posting abstracts of lectures and their presentations; Google Docs - for active work with lecture texts; Google Calendar - to plan and manage educational activities (schedule of classes, consultations, schedule of conferences, reminders of check weeks, deadlines for submitting reports); Google Group - a means of bringing different users together into one group; Google Site - a system for publishing the necessary information on the network; Google Mail - to receive notifications of changes in personal space and to conduct off-line consultations; Google + Hangouts -for online seminars (webinars) and the opportunity to ask questions in the text chat. In the educational process, students also created their own cloud storage on the local network with the help of OwnCloud service, explored the possibilities of its use in their professional activity. The set of outlined services provided by the educational "cloud" of a particular teacher, form his personal information and educational environment. The purpose of each service is shown in Table 5.

Table 5: Purpose of Google Services for teacher competence development

\begin{tabular}{|l|l|}
\hline Services & Purpose \\
\hline Google Docs, Google Spreadsheets & Displays training information \\
\hline $\begin{array}{l}\text { Google Slides, Google Docs, Google } \\
\text { Spreadsheets Google+ Hangouts }\end{array}$ & $\begin{array}{l}\text { Organization of lectures, webinars, } \\
\text { laboratory work, extracurricular work }\end{array}$ \\
\hline Google Calendar, Gmail & $\begin{array}{l}\text { Instructions on the timing of work, } \\
\text { notification of events }\end{array}$ \\
\hline Google Forms & Organization of testing \\
\hline $\begin{array}{l}\text { Google Docs, Google Spreadsheets, } \\
\text { Google Slides }\end{array}$ & $\begin{array}{l}\text { Assessment of group and individual } \\
\text { work }\end{array}$ \\
\hline Gmail, Google Drive, Google Calendar & Provision of educational communications \\
\hline
\end{tabular}

The use of Google Apps Internet Services in distance competence development courses allowed us to fulfil a number of tasks: creating training groups based on each lecture groups by assigning a group address of @groups.live.com type; organization of a calendar of training assignments during the courses with the possibility of automatic notification of the group one week before and subsequent marking of the performance; discussing a separate lecture topic based on OneNoteWebApps notebook; joint editing of the document by several members of the group (this task was most successfully accomplished in the process of carrying out case studies and project assignments, since the results of the discussion with the teacher or other participants of the groups did not require the transfer of files and creation of new documents on the basis of previous ones); posting of educational materials with the possibility of updating them in the current file (making additions; adding comments to individual content elements); receiving assignments by teacher and reporting on their performance 24/7; monitoring the performance of training assignments throughout the courses. 


\section{Results}

Repeated assessments were made according to the same diagnostic methods upon completion of the distance competence development courses by the EG teachers with the use of cloud technologies. The following dynamics were obtained in CG and EG (see Tables 6-10).

Table 6: Results of laboratory work to evaluate the motivational component of teachers' competence

\begin{tabular}{|l|c|c|c|c|c|c|}
\hline \multirow{2}{*}{ Groups } & \multicolumn{6}{|c|}{ Levels of the development of motivational component of competence } \\
\cline { 2 - 7 } & \multicolumn{2}{|c|}{ Basic } & \multicolumn{2}{c|}{ Reproductive } & \multicolumn{2}{c|}{ Creative } \\
\cline { 2 - 7 } & No. of teachers & $\%$ & No. of teachers & $\%$ & No. of teachers & $\%$ \\
\hline $2016-2017$ & 10 & $17 \%$ & 32 & $53 \%$ & 18 & $30 \%$ \\
\hline EG & 20 & $36 \%$ & 23 & $42 \%$ & 12 & $22 \%$ \\
\hline CG & 9 & $20 \%$ & 23 & $51 \%$ & 13 & $29 \%$ \\
\hline $2017-2018$ & 24 & $50 \%$ & 9 & $19 \%$ \\
\hline EG & 15 & $31 \%$ & 24 & 9 & $46 \%$ \\
\hline CG & 2 & $8 \%$ & 11 & $46 \%$ & 11 & $20 \%$ \\
\hline $2018-2019$ & 11 & $37 \%$ & 13 & $43 \%$ & 6 & \\
\hline EG & 2 &
\end{tabular}

Table 7: Results of the performance of final diagnostic work to evaluate the cognitive component of teachers' competence

\begin{tabular}{|c|c|c|c|c|c|c|}
\hline \multirow[t]{3}{*}{ Groups } & \multicolumn{6}{|c|}{ Levels of the development of cognitive component of competence } \\
\hline & \multicolumn{2}{|c|}{ Basic } & \multicolumn{2}{|c|}{ Reproductive } & \multicolumn{2}{|c|}{ Creative } \\
\hline & $\begin{array}{c}\text { No. of } \\
\text { teachers }\end{array}$ & $\%$ & $\begin{array}{c}\text { No. of } \\
\text { teachers }\end{array}$ & $\%$ & $\begin{array}{c}\text { No. of } \\
\text { teachers }\end{array}$ & $\%$ \\
\hline \multicolumn{7}{|c|}{ 2016-2017 } \\
\hline EG & 17 & $28 \%$ & 27 & $45 \%$ & 16 & $27 \%$ \\
\hline CG & 23 & $41.8 \%$ & 26 & $47.3 \%$ & 6 & $10.9 \%$ \\
\hline \multicolumn{7}{|c|}{$2017-2018$} \\
\hline EG & 10 & $22.2 \%$ & 24 & $53.3 \%$ & 11 & $24.4 \%$ \\
\hline CG & 19 & $39.6 \%$ & 23 & $47.9 \%$ & 6 & $12.5 \%$ \\
\hline \multicolumn{7}{|c|}{ 2018-2019 } \\
\hline EG & 4 & $16.7 \%$ & 10 & $41.7 \%$ & 10 & $41.7 \%$ \\
\hline CG & 14 & $47 \%$ & 12 & $40 \%$ & 4 & $13 \%$ \\
\hline
\end{tabular}

Table 8: Results of the defence of the final project work for the evaluation of the activity component of the competence of teachers

\begin{tabular}{|l|c|r|c|r|r|r|}
\hline \multirow{2}{*}{ Groups } & \multicolumn{6}{|c|}{ Levels of the development of activity component of competence } \\
\cline { 2 - 7 } & \multicolumn{2}{|c|}{ Basic } & \multicolumn{2}{c|}{ Reproductive } & \multicolumn{2}{c|}{ Creative } \\
\cline { 2 - 7 } & No. of teachers & \multicolumn{1}{|c|}{ No. of teachers } & $\%$ & No. of teachers & $\%$ \\
\hline $2016-2017$ & 12 & $20 \%$ & 29 & $48 \%$ & 19 & $32 \%$ \\
\hline EG & 23 & $42 \%$ & 27 & $49 \%$ & 5 & $9 \%$ \\
\hline CG & 12 & $26.7 \%$ & 21 & $46.7 \%$ & 12 & $26.7 \%$ \\
\hline $2017-2018$ & $52 \%$ & 18 & $38 \%$ & 5 & $10 \%$ \\
\hline EG & 25 & \multicolumn{7}{|l|}{} \\
\hline CG & 4 & $17 \%$ & 14 & $58 \%$ & 6 & $25 \%$ \\
\hline $2018-2019$ & 10 & $33 \%$ & 20 & $67 \%$ & 0 & $0 \%$ \\
\hline EG & 4 &
\end{tabular}


Table 9: Results of the defence of project research work to evaluate the personal component of teachers' competence

\begin{tabular}{|c|c|c|c|c|c|c|}
\hline \multirow[t]{3}{*}{ Groups } & \multicolumn{6}{|c|}{ Levels of the development of personality component of competence } \\
\hline & \multicolumn{2}{|c|}{ Basic } & \multicolumn{2}{|c|}{ Reproductive } & \multicolumn{2}{|c|}{ Creative } \\
\hline & No. of teachers & $\%$ & No. of teachers & $\%$ & No. of teachers & $\%$ \\
\hline \multicolumn{7}{|c|}{ 2016-2017 } \\
\hline EG & 19 & $32 \%$ & 26 & $43 \%$ & 15 & $25 \%$ \\
\hline CG & 19 & $34.5 \%$ & 28 & $50.9 \%$ & 8 & $14.5 \%$ \\
\hline \multicolumn{7}{|c|}{ 2017-2018 } \\
\hline EG & 8 & $17.8 \%$ & 30 & $66.7 \%$ & 7 & $15.6 \%$ \\
\hline CG & 13 & $27 \%$ & 29 & $60 \%$ & 6 & $13 \%$ \\
\hline \multicolumn{7}{|c|}{ 2018-2019 } \\
\hline EG & 4 & $17 \%$ & 12 & $50 \%$ & 8 & $33 \%$ \\
\hline CG & 10 & $33 \%$ & 18 & $60 \%$ & 2 & $7 \%$ \\
\hline
\end{tabular}

The result of the distance teacher competence development courses was evaluated comprehensively, based on all types of work. Results for distance courses using cloud technologies are presented in Table 10.

Table 10: Changes in teacher competence development during distance courses based on cloud-based learning

\begin{tabular}{|c|c|c|c|c|c|c|}
\hline \multirow[t]{3}{*}{ Groups } & \multicolumn{6}{|c|}{ Summarized levels of the teacher competence development } \\
\hline & \multicolumn{2}{|c|}{ Basic } & \multicolumn{2}{|c|}{ Reproductive } & \multicolumn{2}{|l|}{ Creative } \\
\hline & No. of teachers & $\%$ & No. of teachers & $\%$ & No. of teachers & $\%$ \\
\hline \multicolumn{7}{|c|}{$2016-2017$} \\
\hline EG & 13 & $22 \%$ & 36 & $60 \%$ & 11 & $18 \%$ \\
\hline CG & 24 & $44 \%$ & 25 & $45 \%$ & 6 & $11 \%$ \\
\hline \multicolumn{7}{|c|}{$2017-2018$} \\
\hline EG & 9 & $20 \%$ & 21 & $47 \%$ & 15 & $33 \%$ \\
\hline CG & 16 & $33.3 \%$ & 27 & $56.3 \%$ & 5 & $10.4 \%$ \\
\hline \multicolumn{7}{|c|}{$2018-2019$} \\
\hline EG & 2 & $8 \%$ & 15 & $63 \%$ & 7 & $29 \%$ \\
\hline CG & 12 & $40 \%$ & 16 & $53 \%$ & 2 & $7 \%$ \\
\hline
\end{tabular}

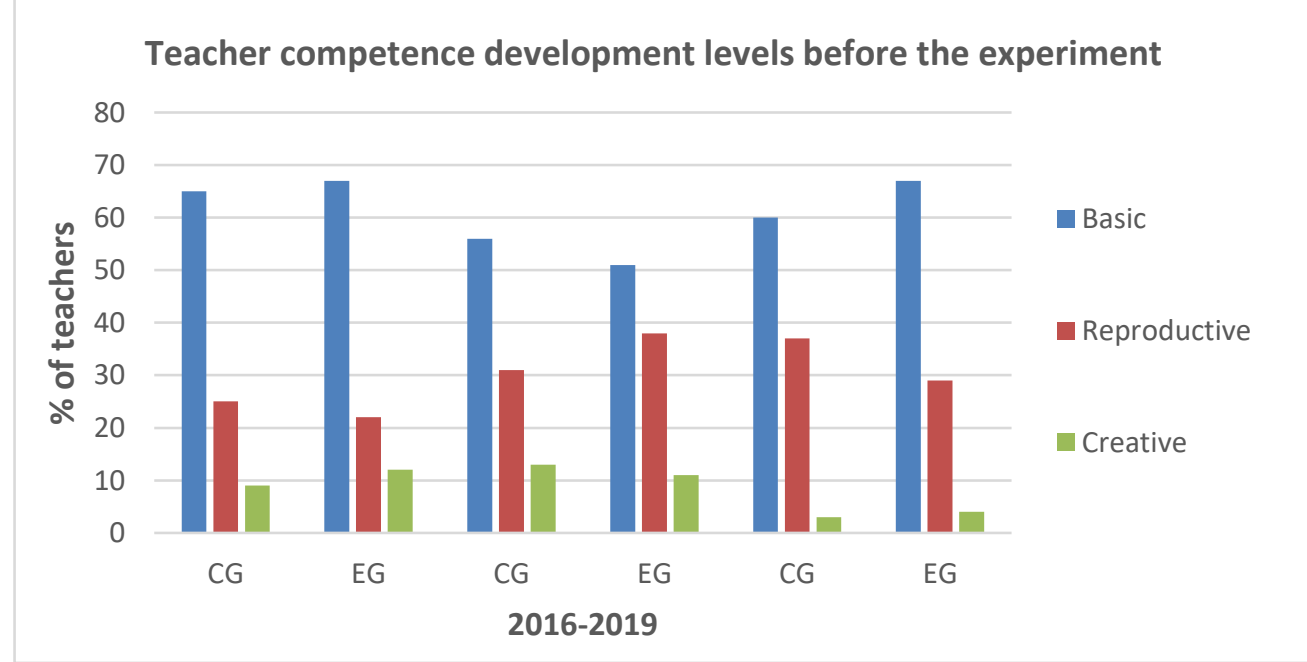

Figure 1: Summarized distribution of teachers by levels of competence development at the pre-experimental stage, $\%$ 


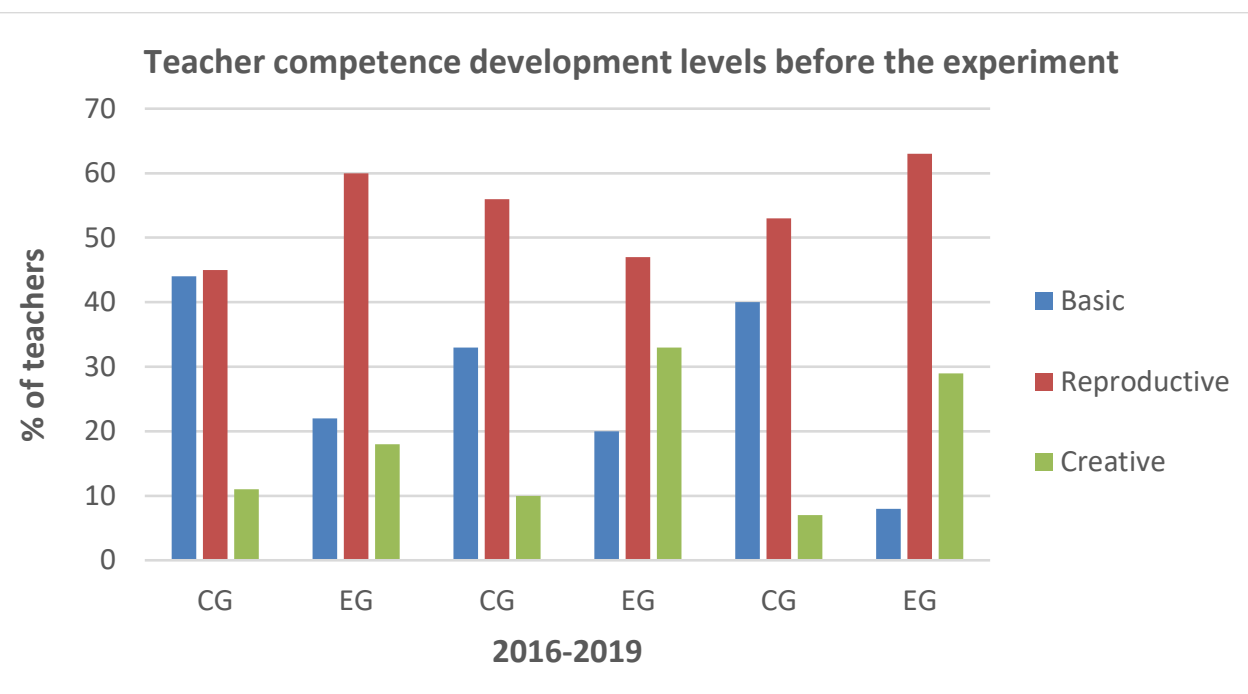

Figure 2: Summarized distribution of teachers by levels of competence development at the post-experimental stage, $\%$

Figures 1 and 2 show the distribution of teachers by levels of competence development before and after the experiment. The results of the statistical data processing compared to the academic results of the CG and EG (after the end of the experiment) made it possible to accept an alternative hypothesis and confirmed the reliability of differences of the characteristics of the compared samples at the level of $95 \%$ (Table 11).

Table 11: The value of the $\chi_{\text {emp }}^{2}$ criterion by years of study after the experiment (comparison of control and experimental groups)

\begin{tabular}{|l|c|c|c|}
\hline Year & $\mathbf{2 0 1 6 - 2 0 1 7}$ & $\mathbf{2 0 1 7 - 2 0 1 8}$ & $\mathbf{2 0 1 8 - 2 0 1 9}$ \\
\hline$\chi_{\text {emp }}^{2}$ & 6.519 & 7.621 & 9.402 \\
\hline
\end{tabular}

Statistical processing of the results of competence development levels in the control group before and after the application of traditional training method (without the use of cloud technologies) indicates more significant changes of the experimental group results before and after the training using cloud technologies (Table 12).

Table 12: The value of the $\chi_{\text {emp }}^{2}$ criterion by years of study after the experiment (comparison of control and experimental groups)

\begin{tabular}{|l|c|c|c|}
\hline Year & $\mathbf{2 0 1 6 - 2 0 1 7}$ & $\mathbf{2 0 1 7 - 2 0 1 8}$ & $\mathbf{2 0 1 8 - 2 0 1 9}$ \\
\hline CG & 5.593 & 6.333 & 2.459 \\
\hline EG & 25.440 & 16.9823 & 18.297 \\
\hline
\end{tabular}

The numerical indicators reflect the effectiveness of the use of cloud-based learning technologies in improving teacher competencies. The given data of tables and figures testify to increase of competence of the EG and CG teachers. In the EG, this increase was, however, more significant (for 2016-2019): on average, there was an increase in the number of teachers with a creative level of competence in 
the EG compared to CG by $17.1 \%$; with reproductive level - by $5.3 \%$; as for the basic level, there were $9.3 \%$ fewer teachers in the EG with this level.

The use of cloud technologies to improve the competence of teachers-practitioner is quite effective and efficient, as evidenced by our distance cloud competence development courses, including the Google Apps Education Edition web portal with its main services. The use of these services extends the cognitive activity of teachers, develops communication and information skills enabling the use of online cloud services and sharing technologies for network cooperation and solving professional problems in the future. The EG teachers have mastered different models of educational activity based on the distribution of the functions of learning activities and the organization of communication between the teacher and students, as well as students with each other using cloud technology.

\section{Discussions}

The use of cloud technologies, in particular the Internet portal Google Apps Education Edition with its main services in the system of advance training of teachers proved to be a pedagogical stimulus for their professional development. The experience of using the above forms and methods of working with Google Apps Education Edition services has shown that the formation, development and improvement of teacher competence is possible through consistent work in the system and the development of all its tools. In addition, distance training courses provided individualization of learning, created preconditions for the transition to personality-oriented learning, allowed teachers to "immerse" in a virtual environment with the ability to simulate educational and professional situations, initiating a willingness to solve problems. The latter is consistent with the findings of Singh and Baheti (2017). When determining the role and service of cloud computing for higher education system proved that cloud services allow rethinking the use of the Internet in the educational process: from access to educational materials of various kinds (text, visual, multimedia) to joint work with the teacher or partners.

This study is consistent with the results of our literature review and contributes to the study of the problem of introducing cloud educational technologies in the system of professional training and building competence of teachers. The results confirmed a previous study conducted by Purwoko, Andayani, Muntar and Diartha (2017), which points out that there is a current need for teachers who focus on continuity of professional education, the expansion of basic skills. Therefore, there is also a need for e-learning, mass open on-line courses. Although this was outside the scope of this study, distance courses reduced the imbalance between excessive efforts to develop teachers' ability to engage in a variety of independent activities to collect, process, store, transfer, produce educational information, and lack of tutor in the development of information skills in the experiment participants.

The study complemented and deepened previous research on the use of cloud technologies in the educational process in the following aspects: the use of cloud computing and technology in education (Bulla et al., 2016); forming feedback and 
metadiscourse at the group level through cloud technologies (Resendes, Scardamalia, Bereiter \& Halewood, 2015) and using open source technologies and open Internet resources to create an interactive learning environment (Kleftodimos \& Evangelidis, 2016). The theoretical, methodological and practical developments have outlined further problem field of research on the technology of integration of cloud services "application as a service" and learning management systems (LMS).

\section{Conclusion}

The use of cloud-based learning technologies in the process of enhancing the competence of teachers enables continuous learning, self-development, raising the level of knowledge of specialists, mass sharing of information and experience regardless of spatial and temporal boundaries, equal chances for self-realization of the participants to the process, creates conditions for teachers to build individual educational trajectories, maximum individualization of the educational process and orientation to conscious independent work. The set of Google Apps Education Edition services we considered meets the requirements for training systems, because they not only facilitate the acquisition of knowledge, but also enhance the skills to use of different strategies for finding information on the Internet, to analyse the information received, effective interaction of teachers in the fulfilment of common tasks and organization of the studied material. Experience in using the said forms and methods of work with Google Apps Education Edition has proven effective development and improvement of teachers' competences during distance courses for systematic work in the systems and development of all their tools. The study of theoretical modules of educational programs in the format of remote technologies, which are implemented on Google Apps platform can be used in the prospect of the development of cloud technologies in higher education. For further research, we propose to develop a mobile application for teachers on Android and IOS to monitor their own achievements, as well as the techniques and methodological support for using Google Apps Education Edition in teaching. It will be very convenient, since mobile phones are always with you and you can complete the task at any time.

\section{Limitations and Implications for the Research}

The results of the study can be challenged because the experiment relied on the experience of only a few higher educational institutions and involved teachers who had no more than 10 years of experience. The quasi-experimental design of the study and a number of variables studied were also limitations of this study. This study experimentally proves that traditional courses in the system of the university-based qualification courses for teachers should soon become a secondary matter, as the digitalization of learning and cloud storage of not only data but also applications changes the approach towards the traditional clientserver model, where the user obtains the minimum required functions. 


\section{References}

Admiraal, W., \& Berry, A. (2016). Video narratives to access student teachers' competence as teachers. Teachers and Teaching. Theory and Practice, 22(1), 21-34. https://doi.org/10.1080/13540602.2015.1023026

Bulla, C., Hunshal, B., \& Mehta, S. (2016). Adoption of cloud computing in education system: a survey. International Journal of Engineering Science and Computing, 6(6), 63-75.

Chhabra, S., \& Dixit, V. S. (2015). Cloud computing: state of the art and security issues. ACM SIGSOFT Software Engineering Notes, 40(2), 1-11. https://doi.org/10.1145/2735399.2735405

Diaby, T., \& Rad, B. B. (2017). Cloud computing: a review of the concepts and deployment models. I. J. Information Technology and Computer Science, 6, 50-58. https:// doi.org/10.5815/ijitcs.2017.06.07

Elmonem, M. A. A., Nasr, E. S., \& Geith, M. H. (2016). Benefits and challenges of cloud ERP systems - A systematic literature review. Future Computing and Informatics Journal, 1(1-2), 1-9. https:// doi.org/10.1016/j.fcij.2017.03.003

Etawi, N. A. A. (2018). A comparison between cluster, grid, and cloud computing. International Journal of Computer Applications, 179(32), 37-42.

Haris, M., \& Khan, R. Z. (2018). A systematic review on cloud computing. International Journal of Computer Sciences and Engineering, 6(11), 632-639. https://doi.org/10.26438/ijcse/v6i11.632639

Hidayat, A., \& Utomo, V. G. (2014). Open source-based m-learning application for supporting distance learning. TELKOMNIKA, 12, 657-664. https://doi.org/10.12928/telkomnika.v12i3

Jain, A., \& Pandey, U. (2013). Role of cloud computing in higher education. International Journal of Advanced Research in Computer Science and Software Engineering, 3(7), 966972.

Kaur, R. (2015). A review of computing technologies: distributed, utility, cluster, grid and cloud computing. International Journal of Advanced Research in Computer Science and Software Engineering, 5(2), 144-148.

Kaur, K. (2016). A review of cloud computing service models. International Journal of Computer Applications, 140(7), 15-18. https://doi.org/10.5120/ijca2016909378

Khedr, A. E., \& Idrees, A. M. (2017). Enhanced e-learning system for e-courses based on cloud computing. Journal of Computers, 12, 10-19. https://doi.org/10.17706/jcp.12.1.10-19

Kleftodimos, A., \& Evangelidis, G. (2016). Using open source technologies and open internet resources for building an interactive video-based learning environment that supports learning analytics. Smart Learning Environments, 3, 9. https:// doi.org/10.1186/s40561-016-0032-4

Lakshminarayanan, R., Kumar, B., \& Raju, M. (2014). Cloud computing benefits for educational institutions. Information Security and Computer Fraud, 2(1), 5-9.

Lauermann, F., \& König, J. (2016). Teachers' professional competence and wellbeing: Understanding the links between general pedagogical knowledge self-efficacy and burnout. Learning and Instruction, 45, 9-19. https:// doi.org/10.1016/j.learninstruc.2016.06.006

Livingston, K. (2014). Teacher educators: hidden professionals? European Journal of Education, 49(2), 218-232. https://doi.org/10.1111/ ejed.12074

Maican, C., \& Lixandroiu, R. (2016). A system architecture based on open source enterprise content management systems for supporting educational institutions. International Journal of Information Management, 36, 207-214. http://dx.doi.org/10.1016/j.ijinfomgt.2015.11.003 
McKenney, S. (2018). How can the learning sciences (better) impact policy and practice? $\begin{array}{llll}\text { Journal of Learning } & \text { Sciences, } & 27(1), & 1-7 .\end{array}$ https://doi.org/10.1080/10508406.2017.1404404

Narayana, K. E., Kumar, S., \& Jayashree, K. (2017). A review on different types of deployment models in cloud computing. International Journal of Innovative Research in Computer and Communication Engineering, 5(2), 1475-1481. https:// doi.org/10.15680/IJIRCCE.2017. 0502029

Nosenko, Yu. H., Popel, M. V., \& Shyshkina, M. P. (2018). The state of the art and perspectives of using adaptive cloud-based learning systems in higher education pedagogical institutions (the scope of Ukraine). In A. E. Kiv, \& V. N. Soloviev (Eds.), Proceedings of the 6th Workshop 18 on Cloud Technologies in Education (CTE 2018) (pp. 173-183). Kryvyi Rih, Ukraine.

Odeh, M., Garcia-Perez, A., \& Warwick, K. (2017). Cloud computing adoption at higher education institutions in developing countries: a qualitative investigation of main enablers and barriers. International Journal of Information and Education Technology, 7(12), 920-927. https://doi.org/10.18178/ijiet.2017.7.12.996

Prescott, J. (2014). Teaching style and attitudes towards Facebook as an educational tool. Active Learning in Higher Education, 15, 117-128. https://doi.org/10.1177/1469787414527392.

Purwoko, A., Andayani, Y., Muntar, I., \& Diartha, I. N. (2017). Efforts in improving teachers' competencies through collaboration between teacher forum on subject matter (MGMP) and pre-service teacher training institution (LPTK). Jurnal Pendidikan IPA Indonesia, 6(1), 11-15. https:// doi.org/10.15294/jpii.v6i1.8858

Resendes, M., Scardamalia, M., Bereiter, C., \& Halewood, C. (2015). Group-level formative feedback and metadiscourse. International Journal of Computer-Supported Collaborative Learning, 10(3), 309-336. https:/ / doi.org/10.1007/s11412-015-9219-x

Simaiya, D., \& Paul, R. K. (2018). Review of various performcae evaluation issues and efficient load balancing for cloud computing. International Journal of Scientific Research in Computer Science, Engineering and Information Technology, 3(3). 943-951.

Singh, U., \& Baheti, P. (2017). Role and service of cloud computing for higher education system. International Research Journal of Engineering and Technology, 4(11), 708-711.

$\mathrm{Su}$, C. H., Tzeng, G.-H., \& Hu, S. K. (2016). Cloud e-learning service strategies for improving e-learning innovation performance in a fuzzy environment by using a new hybrid fuzzy multiple attribute decision-making model. Interactive Learning Environments, 24, 1812-1835.

Sultan, N. (2010). Cloud computing for education: A new dawn? International Journal of Information Management, 109-116. https:// doi.org/10.1016/j.ijinfomgt.2009.09.004

van Leeuwen, A., Janssen, J., Erkens, G., \& Brekelmans, M. (2015). Teacher regulation of cognitive activities during student collaboration: Effects of learning analytics. Computers \& Education, 90, 80-94. https:// doi.org/10.1016/j.compedu.2015.09.006

Vangrieken, K., Dochy, F., Raes, E., \& Kyndt, E. (2015). Teacher collaboration: A systematic review. Educational Research Review, 15, 17-40. http://dx.doi.org/10.1016/j.edurev.2015.04.002

Yousafzai, A., Chang, V., Gani, A., \& Noor, R. M. (2016). Multimedia augmented mlearning: Issues, trends, and open challenges. International Journal of Information Management, 36, 784-792. http://dx.doi.org/10.1016/j.ijinfomgt.2016.05.010 